\title{
Protecting wild yak (Bos mutus) species and preventing its hybrid in China
}

\author{
WANG Shengli ${ }^{1,2^{*}}$, NAN Zhongren ${ }^{1}$, Daniel PRETE ${ }^{2}$ \\ ${ }^{1}$ Gansu Key Laboratory for Environmental Pollution Prediction and Control, College of Earth and Environmental Sciences, \\ Lanzhou University, Lanzhou 730000, China; \\ ${ }^{2}$ Department of Chemistry and Biology, Ryerson University, Toronto M5B2K3, Canada
}

\begin{abstract}
China has made efforts to protect wild yak (Bos mutus) species and prevent the hybrids between wild yak and domestic yak (Bos grunniens) species. At present, wild yak population of a reasonable estimate would be over 70,000 . Due to conservation efforts in environmental protection and ecological construction such as the Wildlife Protection and Nature Reserve Construction Project, the "Grain-for-Green" Project and the Natural Forest Resources Protection Project, the number of wild yaks is increasing. In general, Tibetan Plateau's ecosystem is getting better and its environmental quality shows a gradual improving trend. Tibetan Plateau is one of the world's cleanest regions called as the "Third Pole". In order to preserve the genetic pool of wild yaks, local pastoralists and polices drive off the wild male yaks from the domestic yak herds by making noise (banging washbasins, pots, etc.) or driving cars. Local government also incentivizes the culling of domestic yaks found in wild herds. For the sake of the biological and genetic features of this wild species, and the pastoralist way of life, wild yaks should continuously be protected to keep their genetic integrity. We appeal plans to investigate the gene pollution of wild yaks in some important distribution regions of this species. In the face of hybridizing with domestic yaks, proper guidance is urgently needed to address genetic pollution and protect the genetic integrity of wild yaks.
\end{abstract}

Keywords: wild and domestic yaks; habitat competition; genetic integrity; genetic pollution; pastoralists migration; Altun Mountain National Nature Reserve; Tibetan Plateau

Citation: WANG Shengli, NAN Zhongren, Daniel PRETE. 2016. Protecting wild yak (Bos mutus) species and preventing its hybrid in China. Journal of Arid Land, 8(5): 811-814. doi: 10.1007/s40333-016-0051-6

The main threat to wild yak (Bos mutus) species comes from habitat competition with humans and domestic yak (Bos grunniens) species, and the latter of which mate with wild yaks to produce their hybrids. China has made efforts to protect wild yaks and prevent hybrids between wild yaks and domestic yaks in recent years.

The wild yak species inhabits the Tibetan Plateau (Leslie and Schaller, 2009). It is a State Class I (the highest class) protected animal in China and classified as a globally threatened and vulnerable species by the IUCN Red List. In the late 1800s, wild yak herds were abundant on the Tibetan Plateau, with eye-witness accounts of many hundreds of individuals per day (Bower, 1894). However, in the 1990s, the number of wild yaks dwindled to about 15,000 due to human activities (hunting and habitat competition) (Schaller and Liu, 1996). Due to the controlling and monitoring of illegal poaching and the construction of the nature reserves in and around the

\footnotetext{
*Corresponding author: WANG Shengli (E-mail: wangshengl@lzu.edu.cn)

Received 2016-01-11; revised 2016-02-23; accepted 2016-05-10

(C) Xinjiang Institute of Ecology and Geography, Chinese Academy of Sciences, Science Press and Springer-Verlag Berlin Heidelberg 2016
} 
habitats of wild yaks, the wild yak population was estimated to increase to 19,940 in 2005 (Yao et al., 2006) and to approximately 30,000-50,000 by the end of 2012 (Baidu baike, 2014a). At present, a reasonable estimated number would be over 70,000 (Table 1). Ecosystem on the Tibetan Plateau in general is getting better and its environmental quality shows a gradual improving trend. Tibetan Plateau is one of the world's cleanest regions called as the "Third Pole" (State Council Information of the People's Republic of China Net, 2015). Due to conservation efforts in ecological construction and environmental protection (e.g. the Wildlife Protection and Nature Reserve Construction Project, the "Grain-for-Green” Project and the Natural Forest Resources Protection Project), the number of wild yaks shows an increasing tendency at present.

Table 1 The number of wild yaks in China in recent years

\begin{tabular}{|c|c|c|}
\hline Place & Number & Source \\
\hline Qiangtang National Nature Reserve & 40,000 & China News Net (2015a, b) \\
\hline Altun Mountain National Nature Reserve & 14,850 & Lu et al. (2015) \\
\hline Qinghai province & 12,000 & Estimated from the data in 2003 (Xinhua Net, 2003) \\
\hline Outside the Qiangtang National Nature Reserve in Tibet & 2,000 & $\begin{array}{l}\text { Rough estimated by the authors based on the number } \\
\text { in the Qiangtang National Nature Reserve }\end{array}$ \\
\hline $\begin{array}{l}\text { Outside the Altun Mountain National Nature Reserve in } \\
\text { Xijiang }\end{array}$ & 1,000 & $\begin{array}{l}\text { Rough estimated by the authors based on the number } \\
\text { in the Altun Mountain National Nature Reserve }\end{array}$ \\
\hline Yanchiwan National Nature Reserve & 600 & $\begin{array}{l}\text { Estimated from the data in Wang (2014) and } \\
\text { interview }\end{array}$ \\
\hline Total & 70,450 & \\
\hline
\end{tabular}

Altun Mountain National Nature Reserve is the only natural reserve where wild yaks roam, free from the intermingling of domestic yaks. It is also a priority area of biodiversity conservation in China. The Altun Mountain National Nature Reserve has made some efforts to protect the genetic integrity and promote the repopulation of wild yaks. It has cracked down on the illegal mining of gold, poaching of wild yaks and other damaging activities to protect the ecological environment since 1983 through the establishment of an intelligence network in counties, towns and pastoral areas surrounding the reserve. The network serves to regularly patrol the reserve, maintain checkpoints and monitor human activities by environmental remote sensing satellites (China News Net, 2013; Baidu baike, 2014b; Xinhua Net, 2014). Five checkpoints were set up in the Altun Mountain National Nature Reserve to strengthen the management of mining, tourism and adventure, and staff carry out annual patrols. Additionally, anyone without a passport is not allowed to enter to the reserve in order to ensure that wild animals can live in a relatively undisturbed environment and are less affected by human activities (Baidu baike, 2014b). Ecological environment, especially the natural recovery of vegetation, has been significantly improved in the Altun Mountain National Nature Reserve in Xinjiang in recent years by means of the pastoralists' migration, changing pasture to natural grassland project in China, removing animals' fences, constructing rare wildlife rescue centers and animal hospitals, and strict enforcement of laws (China News Net, 2010; Xinjiang Daily, 2013), all of which have contributed to an increase in the number of wild yaks and other wild animals.

Hybrids between wild yaks and domestic yaks have spawned on the Tibetan Plateau and posed a challenge to pastoralists. When interbreeding occurs, wild males generally run off with the domestic females and it is difficult to domesticate the hybrids. Local pastoralists and polices drive off the wild male yarks by making noise (banging washbasins, pots, etc.; Fig. 1) or driving cars (Fig. 2). Local government also incentivizes the culling of domestic yaks in wild yak herds to preserve the genetic pool of wild yaks (Fig. 3).

The Chinese government will continue to implement environmental and ecological projects (i.e. National Wildlife Protection and Nature Reserve Construction Project) to protect wild yaks and other wildlife. Although some villages have experienced attacks, injuries and even deaths by wild yaks, local pastoralists still continue to protect them, which emphasizes an acute awareness for wildlife conservation. For the sake of preserving the biological and genetic integrity of this 


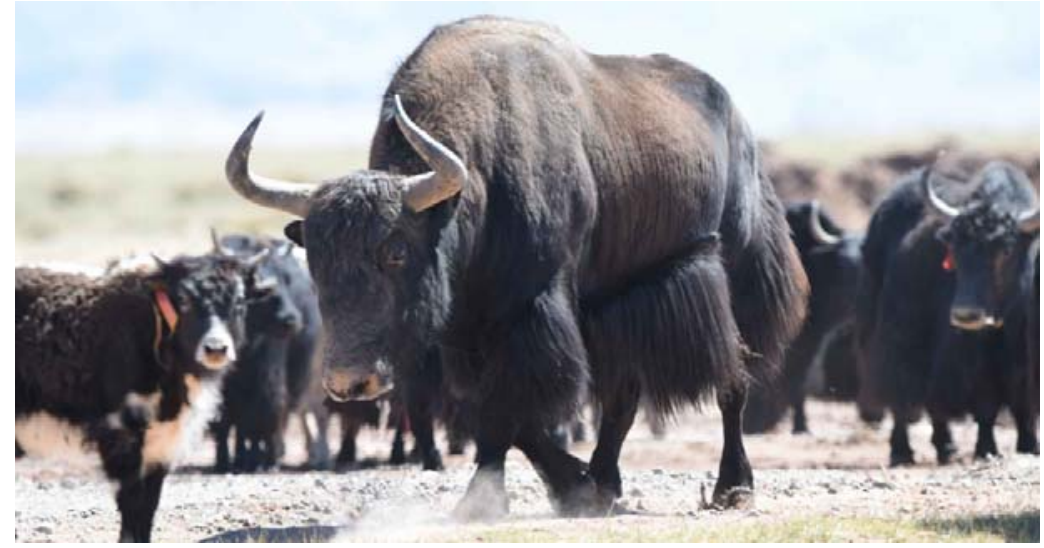

Fig. 1 A wild yak in a domestic yak herd (Photographed by Xilite DABU)

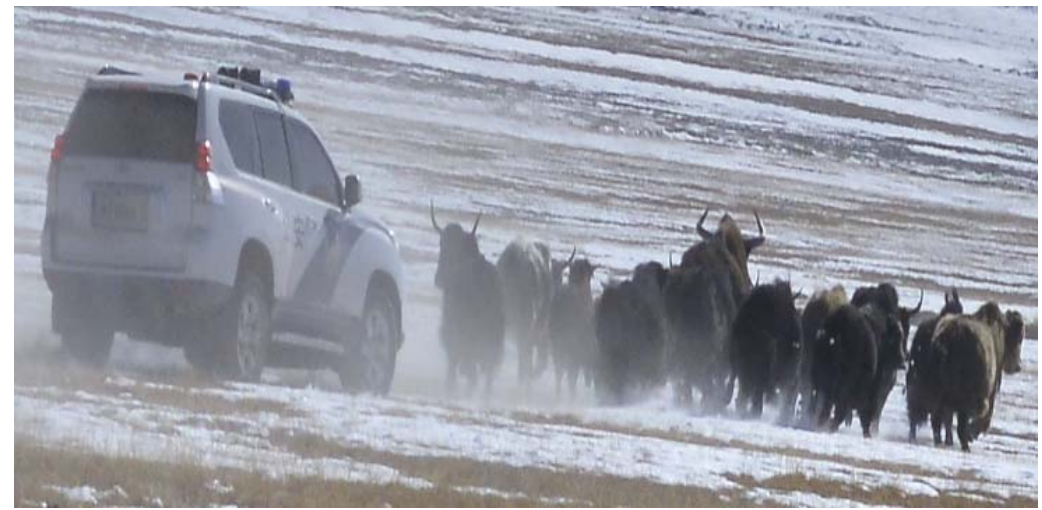

Fig. 2 A police car driving off a wild yak in a domestic yak herd (Photographed by Xilite DABU)

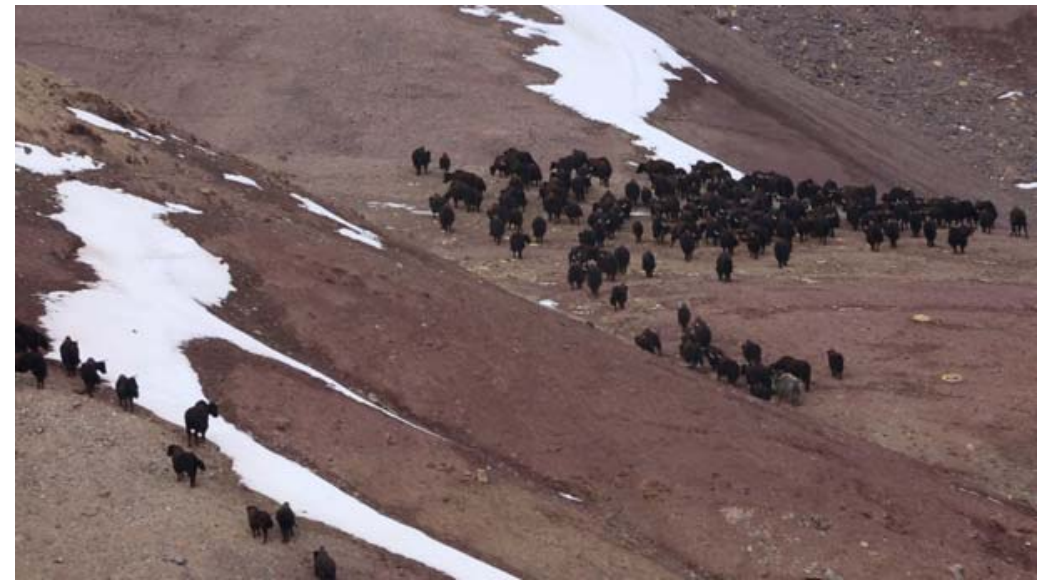

Fig. 3 A white domestic yak in a wild yak herd (Photographed by Xilite DABU)

species, and the pastoralist way of life, wild yaks should continuously be protected.

We appeal for plans to investigate the genetic pollution of wild yaks in some important distribution regions of this species. Genetic screenings probably play a key role in protecting the genetic authenticity of wild yaks. In the face of hybridizing with domestic yaks, proper guidance is urgently needed to manage genetic pollution and protect the genetic integrity of wild yaks. Conservation policies should be made flexible enough to cater to the specific needs of wild yaks for a variety of geographical and genetic distributions such as pure populations, populations with 
few hybridized individuals, widespread hybridization and complete hybridization. We suggest some measures to conserve the pure genes of wild yaks, which include the pastoralists' migration from the nature reserves, direct eradication or sterilization of domestic yaks in regions around the nature reserves, prohibiting the introduction of domestic yaks into the nature reserves and surrounding areas, and preventing the fragmentation and modification of habits. Without effective actions, the genetic integrity of wild yaks may be gradually lost.

\section{Acknowledgments}

This work was supported by the National Natural Science Foundation of China (41571051) and the Fundamental Research Funds for the Central Universities in Lanzhou University (lzujbky-2015-150). We thank WANG Peng in Lanzhou Zuli River Culture Media Ltd. for providing pictures of wild yaks and information about the wild yak population in Yanchiwan National Nature Reserve. We are grateful to the reviewers for their valuable comments to the manscript and Dr. Yousaf MUHAMMAD for his help in the English language editing.

\section{References}

Baidu baike. 2014a. Bos mutus. [2016-01-28]. http://baike.baidu.com/view/32240.htm. (in Chinese)

Baidu baike. 2014b. Altun Mountain National Nature Reserve. [2016-01-28]. http://baike.baidu.com/view/596129.htm. (in Chinese)

Bower H. 1894. Diary of A Journey Across Tibet. London, UK: Rivington, Percival and Company, 286.

China News Net. 2010. Growth in the number of wild animals in the Altun Mountain National Nature Reserve. [2016-01-28]. http://www.chinanews.com/df/2010/08-13/2466171.shtml. (in Chinese)

China News Net. 2013. Eliminating all development of nature reserve in the excuse of solving the legacy problems. [2016-01-28]. http://www.chinanews.com/gn/2013/12-11/5606232.shtml. (in Chinese)

China News Net. 2015a. Number of Tibetan antelope increases to 150,000 in Naqu of Tibet. [2016-01-28]. http://www.chinanews.com/df/2015/08-06/7452516.shtml. (in Chinese)

China News Net. 2015b. Tibet plans to build 76 management and protection stations in Qiangtang National Nature Reserve. [2016-01-28]. http://www.chinanews.com/df/2015/10-11/7563343.shtml. (in Chinese)

Leslie Jr D M, Schaller G B. 2009. Bos grunniens and Bos mutus (Artiodactyla: Bovidae). Mammalian Species, 836: 1-17.

Lu F Y, Shi J B, Zhang Z H, et al. 2015. Surveys of Tibetan antelope, kiang and wild yak in Arjinshan Nature Reserve, Xinjiang, China. Journal of Beijing Normal University (Natural Science), 51(4): 374-381. (in Chinese)

Schaller G B, Liu W L. 1996. Distribution, status, and conservation of wild yak Bos grunniens. Biological Conservation, 76(1): $1-8$.

State Council Information of the People’s Republic of China Net. 2015. "Scientific assessment of environmental change in Tibet Plateau” report. [2016-01-28]. http://www.scio.gov.cn/xwfbh/xwbfbh/wqfbh/2015/20151119/xgbd33811/Document/145586 66/1455866.htm. (in Chinese)

Wang P. 2014. Longing for Eagles' fly (CCTV Documentary). [2016-01-28]. http://jishi.cntv.cn/2014/11/26/VIDA1416985968589895.shtml. (in Chinese)

Xinhua Net. 2003. Sharp decline in the number of wild yaks in Qinghai (less than 10,000). [2016-01-28]. http://news.sohu.com/59/96/news208789659.shtml. (in Chinese)

Xinhua Net. 2014. "Illegal crossing” threat to ecological security in the Altun Mountain National Nature Reserve. [2016-01-28]. http://news.xinhuanet.com/2014-11/04/c_1113110982.htm. (in Chinese)

Xinjiang Daily. 2013. Ecological environment has been significantly improved in the Altun Mountain National Nature Reserve in Xinjiang in recent years. [2016-01-28]. http://www.gov.cn/gzdt/2013-09/25/content_2494566.htm. (in Chinese)

Yao J, Yang B H, Yan P, et al. 2006. Analysis on habitat variance and behaviour of Bos gruiens in China. Acta Prataculturae Sinica, 15(2): 124-128. (in Chinese) 